Article

\title{
Corrosion Resistance Properties of Aluminum Coating Applied by Arc Thermal Metal Spray in SAE J2334 Solution with Exposure Periods
}

\author{
Han-Seung Lee ${ }^{1}$, Jitendra Kumar Singh ${ }^{1,2}$, Mohamed A. Ismail ${ }^{3, *}$ and Chinmoy Bhattacharya ${ }^{2}$ \\ 1 Department of Architectural Engineering, Hanyang University, 1271 Sa 3-dong, Sangrok-gu, Ansan 426-791, \\ Korea; ercleehs@hanyang.ac.kr (H.-S.L.); jk200386@hanyang.ac.kr (J.K.S.) \\ 2 Department of Chemistry, Indian Institute of Engineering Science and Technology, Shibpur, Howrah 711103, \\ India; c.bhattacharya@rediffmail.com \\ 3 Department of Civil and Construction Engineering, Faculty of Engineering and Science, Curtin University \\ Sarawak, CDT 250, 98009 Miri, Malaysia \\ * Correspondence: m.abdelkader@curtin.edu.my; Tel.: +60-85-443939 (ext. 3962); Fax: +60-85-443837
}

Academic Editor: Hugo F. Lopez

Received: 31 December 2015; Accepted: 26 February 2016; Published: 5 March 2016

\begin{abstract}
Arc thermal metal spray coating provides excellent corrosion, erosion and wear resistance to steel substrates. This paper incorporates some results of aluminum coating applied by this method on plain carbon steel. Thereafter, coated panels were exposed to an environment known to form stable corrosion products with aluminum. The coated panels were immersed in Society of Automotive Engineers (SAE) J2334 for different periods of time. This solution consists of an aqueous solution of $\mathrm{NaCl}, \mathrm{CaCl}_{2}$ and $\mathrm{NaHCO}_{3}$. Various electrochemical techniques, i.e., corrosion potential-time, electrochemical impedance spectroscopy (EIS) and the potentiodynamic were used to determine the performance of stimulants in improving the properties of the coating. EIS studies revealed the kinetics and mechanism of corrosion and potentiodynamic attributed the formation of a passive film, which stifles the penetration of aggressive ions towards the substrate. The corrosion products that formed on the coating surface, identified using Raman spectroscopy, were Dawsonite $\left(\mathrm{NaAlCO}_{3}(\mathrm{OH})_{2}\right)$ and $\mathrm{Al}(\mathrm{OH})_{3}$. These compounds of aluminum are very sparingly soluble in aqueous solution and protect the substrate from pitting and uniform corrosion. The morphology and composition of corrosion products determined by scanning electron microscopy and energy dispersive $X$-ray analyses indicated that the environment plays a decisive role in improving the corrosion resistance of aluminum coating.
\end{abstract}

Keywords: passive film; arc thermal metal spray; electrochemical impedance spectroscopy; Raman spectroscopy; SEM; X-ray diffraction

\section{Introduction}

Steel is being used everywhere in world due to its broad application. Steel has inherent mechanical properties to a proper extent, but there are some problems related to corrosion, especially in aqueous, dry and atmospheric conditions. The atmospheric corrosion of steel is a serious problem and different types of organic and inorganic coatings have been developed to extend the service life of structures made from steel. Besides coatings on structural steel, stainless steel is being used in infrastructure but is not economical. The coating of steel with aluminum metal is found to provide protection in industrial and marine environments. Different techniques for the application of aluminum coating such as hot dip, aluminizing, high velocity oxy fuel, plasma spray and arc thermal spray methods, have been developed. Among these techniques, arc thermal spray methods are convenient, economical and logistically feasible [1,2]. To protect bridges, strobes, pipelines and other large steel structures for long-term protection in industrially polluted, saline and open atmospheres, the use of $\mathrm{Al}$ coating with 
the thermal spray process had been reported about a century ago [3]. The application of coatings with the arc thermal process is very easy and convenient. In this process, prior to the application of the coating, the target surface should be proper cleaned and sandblasted because a good anchoring for the coating is required. This instrument gun is portable and a power supply is needed for the arcing of wires. Before applying the coating, it must be ensured that there is a proper power supply at the application location and a fuel tank necessary for the flame spray. In the arc thermal metals spray process, twin wires are used for coating and an electric arc melts the tips of these wires. After arcing, the wires melt and atomized by hot air which impinges on the target (substrate). The melted metal droplets adhere onto the substrates and are cooled at room temperature, resulting in the formation of a coating [4]. Due to the high speed of spraying and the sudden cooling of melted metal droplets spread at the substrate, some invisible porosity in the deposited coating and shrinkages develops [1,5-8].

To fill the pores or defects in coatings, various methods have been suggested. The most popular method is metal-polymeric dual coating. The application of polymeric coating is better for shorter durations of exposure with regard to corrosion protection. In the case of longer durations, it causes cracking or premature distresses in the coating. It is caused due to a difference in the thermal expansion coefficients of the metal-polymer. Li et al. (2006) and Muhamad et al. (2013) have carried out research into the protection of steel by means of $\mathrm{Al}$ coating through an arc thermal spray process with a filler; they reported enhanced corrosion resistance properties for this coating after eight years of exposure in a coastal environment $[9,10]$.

A search of the literature reveals that very limited information is available on the use of fillers or other techniques to block the porosity of arc thermal sprayed aluminum coating. To enhance the properties of coatings, researchers are using different pseudo alloys and rare earth metals for corrosion resistance properties in aggressive environments [11,12]. Due to the anodic nature of Al metal, it sacrificially protects the steel surface. During the corrosion process of the Al coating, its corrosion products are deposited on the coating surface. These corrosion products fill the pores of the coating and enhances the corrosion resistance performance of the Al coating by arc thermal spray process. The most popular test environment to assess the performance of the coatings is $3.5 \mathrm{wt}$. \% sodium chloride. The corrosion performance of Al coatings in coastal and open industrially polluted environments showed the enhanced corrosion resistance properties for longer duration of exposure due to the sacrificial nature of $\mathrm{Al}$ metal [13] and the formation of naturally occurring protective corrosion products on the coating surface [14]. These protective corrosion products block the pores of the coating and increase the corrosion resistance properties of the coating. For studies on atmospheric corrosion, the coating should be exposed for longer durations to assess its corrosion resistance properties [15].

A search of the literature also shows that there is possibly no such research being carried out by anyone to study the performance of $\mathrm{Al}$ coatings in the laboratory in the presence of stimulants. Generally, stimulants are induced in nature for the corrosion of metals and alloys. In the atmosphere, there are many stimulants present, i.e., carbonates, chlorides, sulphates, nitrates, etc. The atmospheric corrosion for coated samples requires a significant amount of time to determine their performance and depends on the aggressiveness of the environment [15]. However, this study simulates the aggressive atmospheric environment to form naturally occurring corrosion products to block the pores of the coating in immersion conditions. We allowed the deposited coating to age in an environment having a lower concentration of sodium chloride, sodium bicarbonate and calcium chloride. The idea was to develop sparingly soluble corrosion products under immersion conditions and block the porosity in the coating. The objectives of this study are as follows:

1. To evaluate the performance of Al coatings in immersion conditions of SAE J2334 solution;

2. To determine the kinetics and mechanism of corrosion process for Al coatings applied by arc thermal metals spray in the presence of stimulants, i.e., carbonate and chloride ions;

3. To study the role of stimulants on the formation of corrosion products on the surface of $\mathrm{Al}$ coatings in SAE J2334 solution; 
4. To study the nature of corrosion products formed on $\mathrm{Al}$ coating surface in presence of stimulants, i.e., carbonate and chloride ions.

\section{Materials and Methods}

\subsection{Process of Coating}

An arc thermal metal spray coating with commercially pure $\mathrm{Al}(99.95$ wt. \%) wires of $1.6 \mathrm{~mm}$ diameter was applied to a sandblasted mild steel substrate. The chemical composition of the mild steel is shown in Table 1. The dimension of the samples was $80 \mathrm{~mm} \times 60 \mathrm{~mm} \times 1.0 \mathrm{~mm}$. The thickness of the coating was measured using a non-destructive technique with Elcometer 456 at different places, and was approximately $100 \mu \mathrm{m}( \pm 5 \mu \mathrm{m})$. The details of the spraying parameters are shown in Table 2 [16-18].

Table 1. Chemical composition of steel (wt. \%).

\begin{tabular}{ccccccccc}
\hline \multicolumn{10}{c}{ Chemical Composition (wt. \%) } \\
\hline $\mathrm{C}$ & $\mathrm{Si}$ & $\mathrm{Mn}$ & $\mathrm{P}$ & $\mathrm{S}$ & $\mathrm{Cu}$ & $\mathrm{Cr}$ & $\mathrm{Ni}$ & $\mathrm{Fe}$ \\
0.240 & 0.260 & 0.950 & 0.016 & 0.008 & 0.020 & 0.040 & 0.030 & balance \\
\hline
\end{tabular}

Table 2. Detail parameters used in the high frequency arc thermal metal spray process [16-18].

\begin{tabular}{cc}
\hline Parameters (unit) & Quantitative Value \\
\hline Air Pressure (bar) & $4-6$ \\
Spraying distance (cm) & $15-25$ \\
Spraying Voltage (V) & 30 \\
Spraying Current (A) & 200 \\
\hline
\end{tabular}

In this method, Al metal is being melted at an arc point through a circular slit by hot air stream in which metal can be diffused and cooled at room temperature (Figure 1). The detail of the spraying parameters was maintained on the basis of earlier work done by different researchers [16-18]. The diffused layer of coating was formed on the steel substrate. During the solidification and diffusion of metals towards the steel substrate, some pores are being formed on the coating. The pores are different sizes and contribute to getting moisture, oxygen and other aggressive ions from the atmosphere.

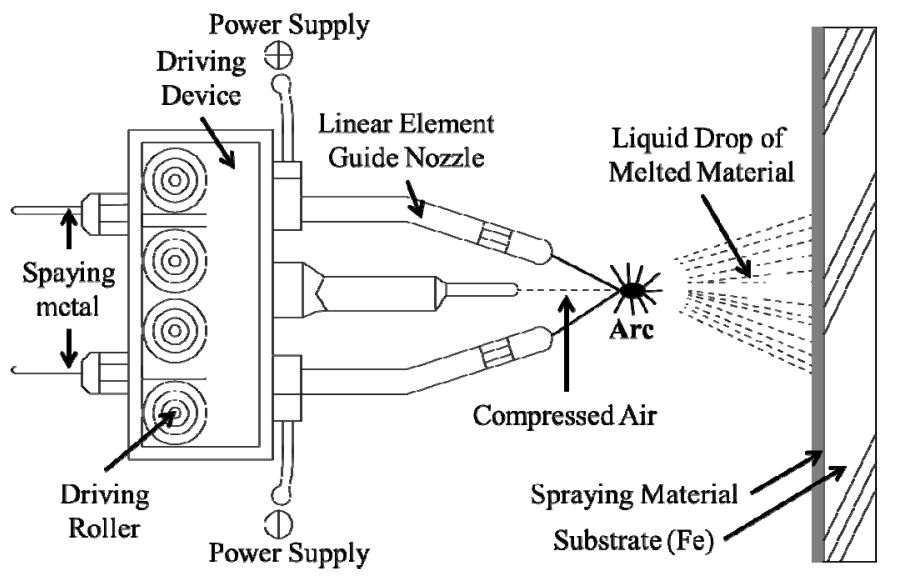

Figure 1. Schematic diagram of the arc thermal metal spay process.

After the application of the coating on the steel substrate, the adhesion of the coating strength was measured based on to ASTM D4541 [19]. 


\subsection{Electrochemical Studies}

The electrochemical studies were performed with the SAE J2334 (Society of Automotive Engineers) solution [20-24]. It consists of 0.5 wt. $\% \mathrm{NaCl}, 0.1$ wt. $\% \mathrm{CaCl}_{2}$ and 0.075 wt. $\% \mathrm{NaHCO}_{3}$. The $\mathrm{Al}$ coating is directly immersed in the SAE J2334 solution and it is likely identical to atmospheric weathering conditions, which contain chloride and carbonate ions in open industrially polluted environments. The chemicals used were of analytical grade. The $\mathrm{pH}$ of the SAE J2334 solution was measured at room temperature and was 9.17. These chemicals were dissolved in double distilled water. Prior to the start of the experiments, the samples were exposed to the solution and stabilized the potential with potentiostat. These studies were performed by three electrode systems where the coated sample worked as a working electrode (WE), platinum wire as a counter electrode (CE) and silver-silver chloride as a reference electrode (RE). The electrochemical setup is shown in Figure 2. The sample holder area of working electrode was $0.78 \mathrm{~cm}^{2}$ and it was fixed for all samples.

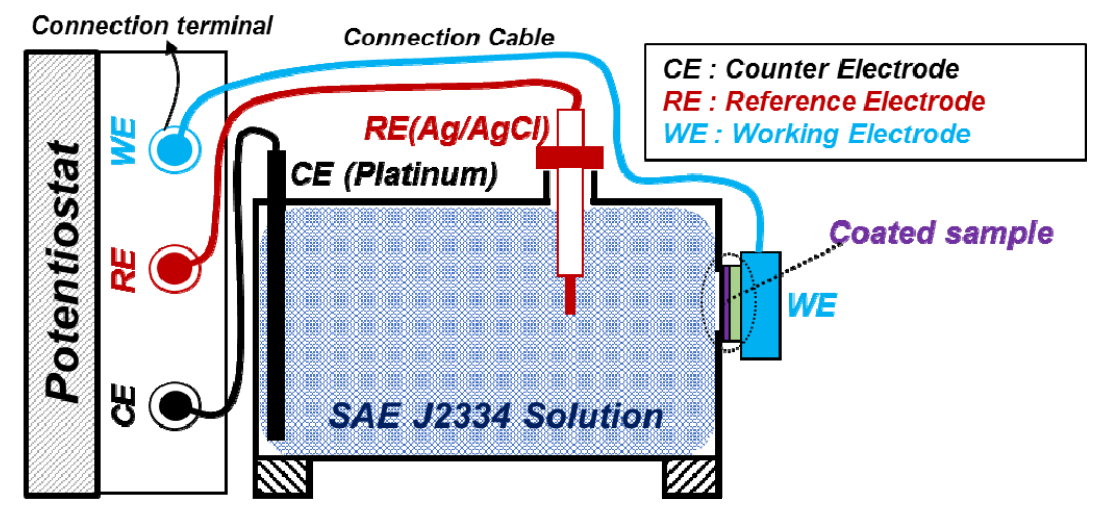

Figure 2. Schematic diagram of the electrochemical setup.

The electrochemical impedance spectroscopy (EIS) studies were carried out by changing the frequency of $10 \mathrm{mV}$ sinusoidal voltage from $100 \mathrm{kHz}$ to $0.01 \mathrm{~Hz}$. The DC polarization studies were performed at a $1 \mathrm{mV} / \mathrm{s}$ scan rate from $-0.4 \mathrm{~V}$ to $+0.8 \mathrm{~V} \mathrm{Vs}$ open circuit potential [11,25]. The potentiostat was VersaSTAT (Princeton Applied Research, Oak Ridge, TN, USA) and data analysis was carried out using Metrohm Autolab Nova 1.10 software (Ionenstrasse, Herisau, Switzerland) by fitting the experimental data in the constant phase element (CPE) model. All electrochemical studies were carried out at room temperature $\left(27 \pm 1^{\circ} \mathrm{C}\right)$.

\subsection{Characterization of Coating and Corrosion Products}

The morphology of coating and corrosion products were determined by Scanning Electron Microscope (SEM, Philips XL 30, North Billerica, MA, USA) operated at $15 \mathrm{kV}$, equipped with an Energy Dispersive X-ray Spectroscopy (EDS) tool for elemental analysis. Prior to taking the image of the SEM, samples were coated with platinum to increase the conductivity and avoid the charging effect of samples. The X-ray diffraction (XRD, Philips X'Pert-MPD, EA Almelo, The Netherland) studies of the coating was performed by using $\mathrm{Cu} \mathrm{K} \alpha$ radiation $(\lambda=1.54059 \AA)$ generated at $40 \mathrm{kV}$ and 100 mA. The Raman spectroscopy (Renishaw RM 1000, Mercury Dr., Champaign, IL, USA) of corrosion products was carried out by using a He-Ne laser beam of $632.8 \mathrm{~nm}$ wavelength. The power of the laser was kept at $10 \mathrm{~mW}$ to avoid the transformation of corrosion products due to the heating effect. The collection time was $10 \mathrm{~s}$ and the ranges of Raman shift between $200 \mathrm{~cm}^{-1}$ and $3200 \mathrm{~cm}^{-1}$. The locations of the specimens to be studied were focused through an Olympus microscope at a magnification of 20 (Mercury Dr., Champaign, IL, USA). The sample holder had a motorized platform with Jokey (Mercury Dr., Champaign, IL, USA) in order to have fine focusing and mapping at a desired location. Prior to the analysis of the samples, the instrument was calibrated by using pure silicon at the peaks of $520 \mathrm{~cm}^{-1}$. 


\section{Results and Discussion}

\subsection{Characterization of the Arc Thermal Sprayed Coatings}

The coating was characterized by SEM and XRD. The top surface and cross section morphology of the coating by the SEM are shown in Figure 3. This coating had many defects as shown by the arrow marks (Figure 3a,b), which is a well-known feature for such coatings [6,8]. The melted metal particles continuously impinged on the base metals and formed layer upon layer of plate-like microstructures [26]. With the high velocity deposition of the coating and after rapid cooling at room temperature, the air diffused from the coating surface resulted in the formation of a splashed zone or pores/defects on the coating surface $[27,28]$. These splash zones contributed to getting moisture and other aggressive ions from the atmosphere [29,30]. A chemical analysis of the coating is shown in the EDS spectra (Figure 3c). On the surface of coating, $2.20 \mathrm{wt}$. \% oxygen was present; this oxygen might have come during the spraying of the coating at high temperature and in-flight particles oxidation from the atmosphere [31].
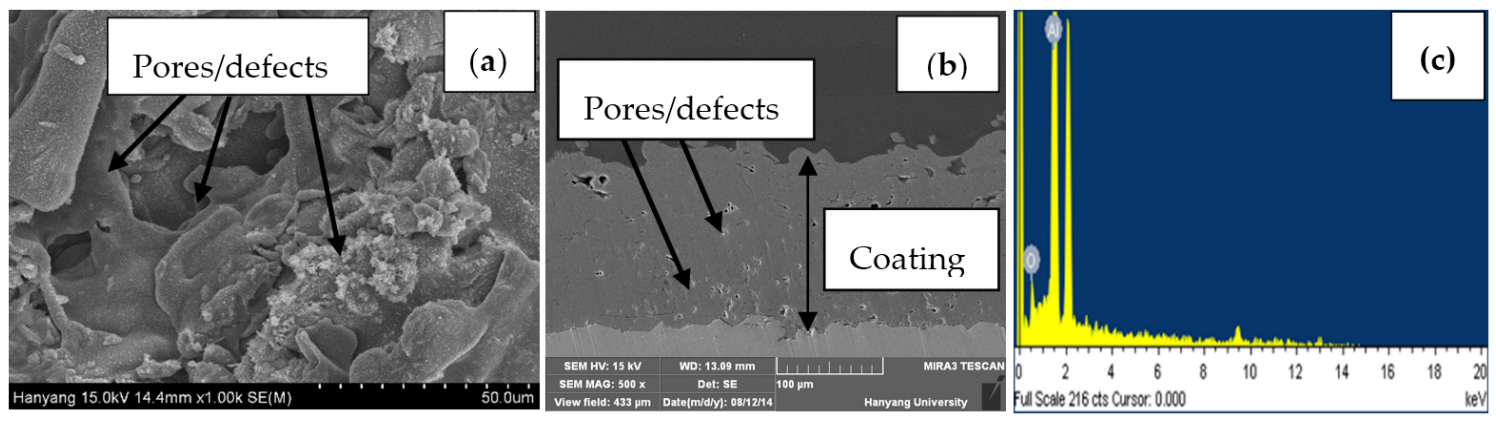

Figure 3. SEM images (a) top surface, (b) cross section and (c) EDS of the Al coating by the arc thermal metal spray process.

The XRD of the coating is shown in Figure 4 and, from this figure, it can be seen that after the spraying of $\mathrm{Al}$ using the arc thermal metal spray process, pure $\mathrm{Al}$ is present. There is no other phase present on the coating surface besides $\mathrm{Al}$, because the oxygen concentration is very low and the oxide phase which might be present is beyond the limit of XRD detection.

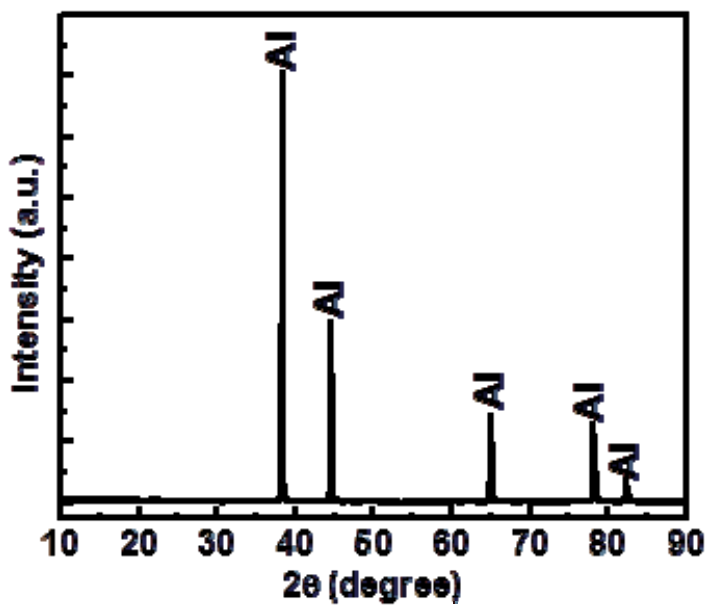

Figure 4. The XRD of aluminum coating using the arc thermal metal spray process.

The bond strength of the coating was measured and is presented in Table 3 . The coating was applied on a sandblasted surface for proper adhesion to the steel substrate. In this process, 
$40 \mathrm{~mm} \times 40 \mathrm{~mm}$ of selected dimensions of the coating substrate were used for the adhesion test. The bond strength measurements were carried out for four samples, and the average was taken for all samples. The average coating strength was $4.86 \mathrm{MPa}$ and the adhesion also depends on the feedstock value $[32,33]$. The bond adhesion of applied coating was low and is due to more selection of the coating surface area.

Table 3. Bond adhesion test results of the $\mathrm{Al}$ coating using the arc thermal metal spray process.

\begin{tabular}{cc}
\hline Sample Number & Bond Strength (MPa) \\
\hline 1 & 4.81 \\
2 & 4.97 \\
3 & 4.83 \\
4 & 4.82 \\
Average & 4.86 \\
\hline
\end{tabular}

\subsection{Electrochemical Studies of Coating}

\subsubsection{Potentiodynamic Studies}

The corrosion resistance properties of the coating were evaluated in the SAE J2334 solution. Prior to this, the coating was exposed in solution for $1 \mathrm{~h}$ to stabilize its potential. To ensure the stabilized potential, this experiment was carried out with a potentiostat. Thereafter, potentiodynamic studies were carried out. It can be seen from Figure 5 that the coated substrate exhibited more resistance to corrosion than bare steel, and that the corrosion potential $\left(E_{\text {corr }}\right)$ for the coated substrate is more active. Due to more active $E_{\text {corr }}$ of the coating in the SAE J2334 solution, it was found that Al metal provided cathodic protection to the steel substrate [13]. The electrochemical data are shown in Table 4, which were extracted from fitting these curves in the Tafel region. The $E_{\text {corr }}$ values are $-0.689 \mathrm{~V}$ and $-0.717 \mathrm{~V}$, and the $I_{\text {corr }}$ (corrosion current density) values are $15.22 \mu \mathrm{A} / \mathrm{cm}^{2}$ and $12.96 \mu \mathrm{A} / \mathrm{cm}^{2}$ for bare steel and Al coating, respectively. Once the $I_{\text {corr }}$ is determined, the corrosion rate $(\mathrm{CR})$ can be calculated using Faraday's law and putting these value in the following equation [34]:

$$
\text { Corrosionrate }(\mu \mathrm{m} / \text { year })=\frac{3.27 I_{\text {corr }} \cdot \text { E.W. }}{d}
$$

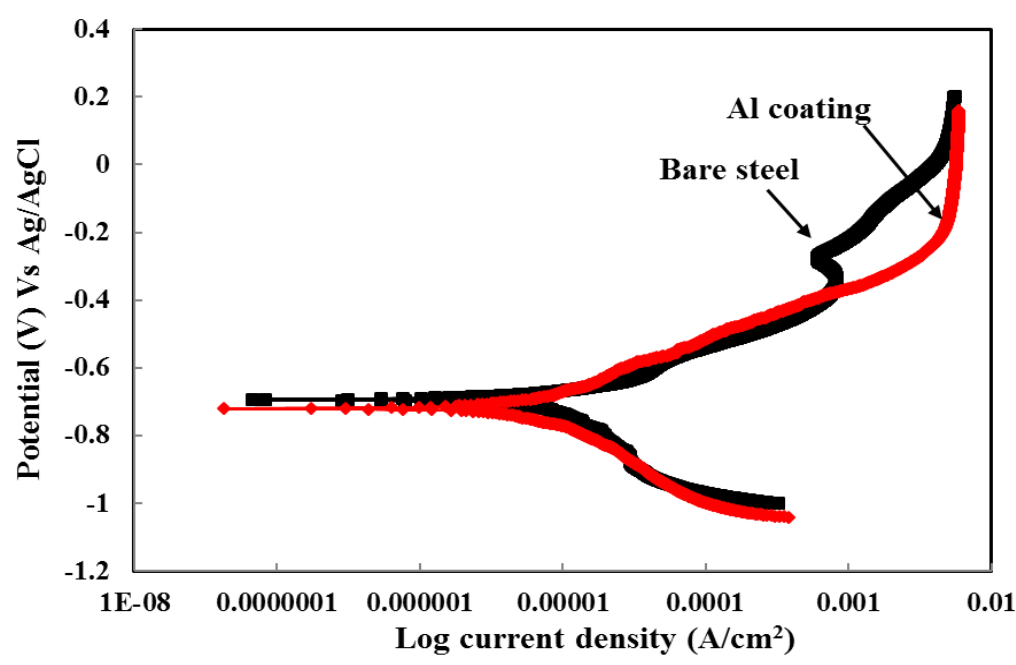

Figure 5. Potentiodynamic studies of samples in the SAE J2334 solution after $1 \mathrm{~h}$ of exposure. 
Table 4. Electrochemical parameters extracted from potentiodynamic polarization curves in the SAE J2334 solution after $1 \mathrm{~h}$ of exposure.

\begin{tabular}{ccccc}
\hline \multirow{2}{*}{ Sample ID } & \multicolumn{4}{c}{ Electrochemical Parameters } \\
\cline { 2 - 5 } & $\boldsymbol{E}_{\text {corr }}(\mathbf{V})$ vs. $\mathbf{A g} / \mathbf{A g C l}$ & $\boldsymbol{R}_{\mathbf{p}}\left(\boldsymbol{\Omega} \cdot \mathbf{c m}^{2}\right)$ & $\boldsymbol{I}_{\text {corr }}\left(\boldsymbol{\mu A} \cdot \mathbf{c m}^{-2}\right)$ & $\mathbf{C R}(\mu \mathrm{m} /$ year $)$ \\
\hline Bare steel & -0.689 & 4155.0 & 15.22 & 176.82 \\
Al coating & -0.717 & 5634.0 & 12.96 & 141.26 \\
\hline
\end{tabular}

The corrosion rate in Equation (1) is expressed in micrometers per year ( $\mu \mathrm{m} /$ year), corrosion current density $\left(I_{\text {corr }}\right)$ in $\mu \mathrm{A} / \mathrm{cm}^{2}$. The $I_{\text {corr }}$ was obtained by dividing total surface area of the working electrode in the corrosion current, E.W. represents the equivalent weight $(\mathrm{g} / \mathrm{mole})$ and $d$ is the density $\left(\mathrm{g} / \mathrm{cm}^{3}\right)$.

From Table 4 it can be seen that the corrosion rate (CR) for bare steel is higher than Al coated substrate in the SAE J2334 solution. The corrosion current density is slightly lower for Al coated substrate than for bare steel, which indicates the lower corrosion rate of coated substrate. The polarization resistance, $\left(R_{\mathrm{p}}\right) 5634 \Omega \cdot \mathrm{cm}^{2}$ for Al coating and $4155 \Omega \cdot \mathrm{cm}^{2}$ for bare steel, are calculated after fitting the curve in the Tafel region. These results indicate that the bare steel is susceptible to this environment, but a coated substrate provides protection. The bare steel attained another breakdown potential (approximately $-0.270 \mathrm{~V}$ ) at a more anodic side due to the accumulation of corrosion products on the bare steel surface, which were formed during the initial exposure. Coated steel exhibited passive behavior during the anodic polarization, while bare steel exhibited more pitting and it did not form a passive film (Figure 5). From this study, it can be said that the coated substrate has the passivating tendency in the SAE J2334 solution. Higher $R_{\mathrm{p}}$ and lower $I_{\text {corr }}$ correspond to a high degree of protection provided by Al coating, while bare steel exhibited the reverse. These results suggested that the bare steel is more susceptible to corrosion in the presence of such stimulants.

\subsubsection{Potential-Time Studies of Al Coating in SAE J2334 Solution.}

Coatings were exposed to the SAE J2334 solution and the corrosion potential was measured with the exposure periods (Figure 6). The active potential range was from $-0.616 \mathrm{~V}$ to $-0.910 \mathrm{~V} \mathrm{for} 1 \mathrm{~h}$ to $72 \mathrm{~h}$ (inset Figure 6), respectively. The shifting of potential may be due to the coating surface's connected porosity, which makes the steel as cathode and gives a mixed potential value. For the initial exposure of the coating in the solution, it activates the surface due to the presence of activating agents such as chloride and carbonates in the solution, while more defects or active sites on the coating surface enhances the dissolution [35]. At the time of exposure, it was passivating the surface, but not actively. Therefore, at time of the initial exposure, the passive film was weak on the surface but once there was a significant amount of reaction between the solution and the coating surface, the surface became more protective. This resulted in a shifting of potential towards the nobler side. After $72 \mathrm{~h}$ of exposure, the potential ennobling up to $384 \mathrm{~h}(-0.810 \mathrm{~V})$ indicated the passive behavior of the coating and determined the coating characteristics in this solution. The shifting of the corrosion potential towards the nobler side is attributed to the formation of passive film on the coating/solution interface [36-38]. The formation of passive film enables the higher degree of protection against the coating in the SAE J2334 solution. Thus, the Al coating exposed in simulated accelerated atmosphere conditions provided improved protection against deterioration due to the formation of passive film.

\subsubsection{Electrochemical Impedance Spectroscopy (EIS) Evaluation of Coating in SAE J2334 Solution}

EIS is a very useful technique for the determination of corrosion characteristics at the solution/coating interface. The EIS evaluation of Al coatings was performed in the SAE J2334 solution at the open circuit potential with exposure periods. The EIS graphs are shown in Figures 7 and 8 . The Al coating applied using the arc thermal metal spray methods provided protection to the steel substrate and can be described by EIS studies. 


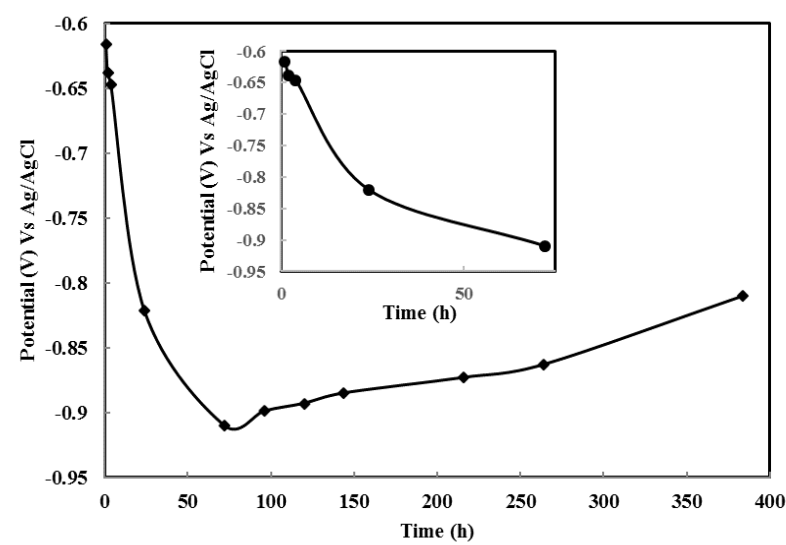

Figure 6. Corrosion potential-time plots of Al coated steel in SAE J2334 solution with exposure periods.

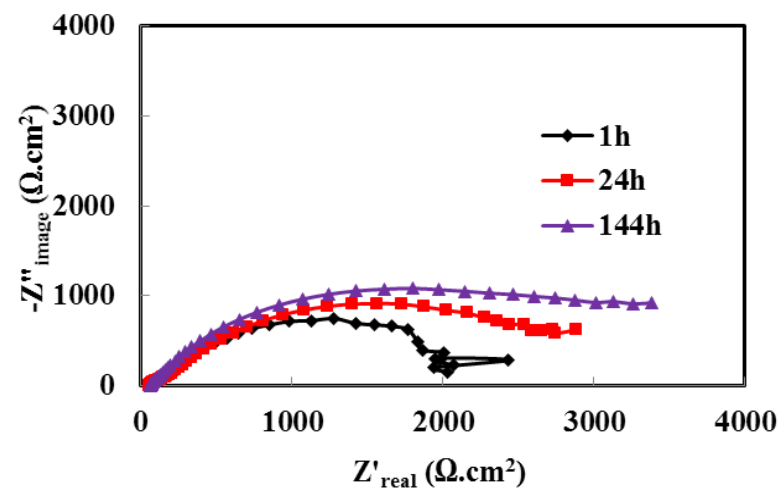

(a)

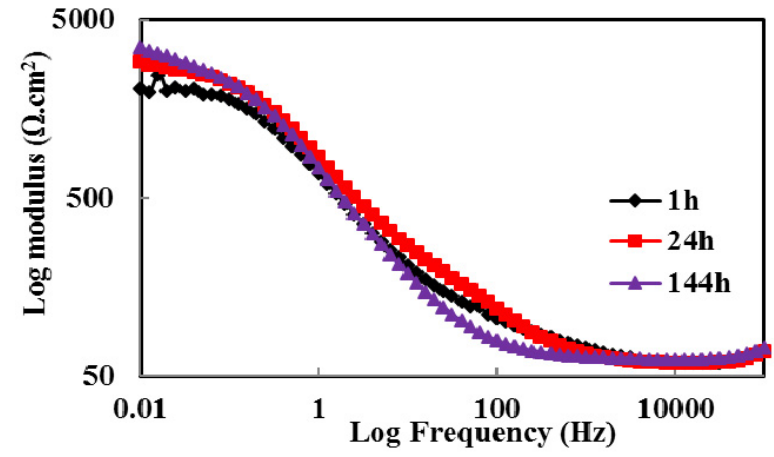

(b)

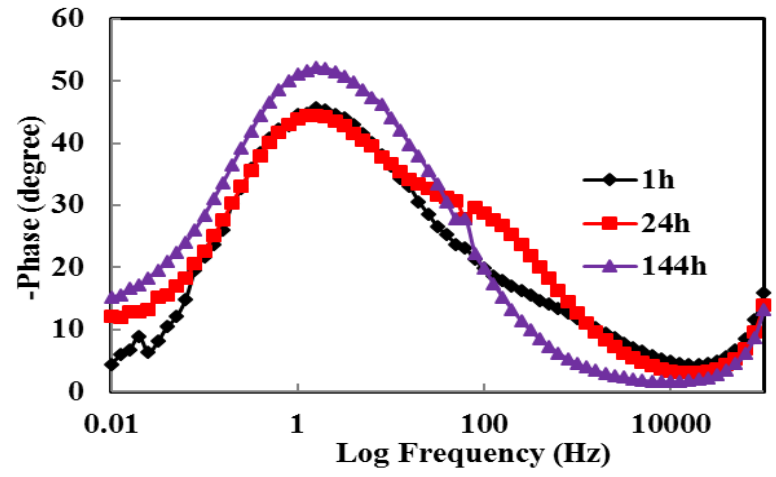

(c)

Figure 7. Electrochemical impedance studies of Al coating in SAE J2334 solution with exposure periods (a) Nyquist, (b) Bode impedance-frequency, (c) Bode phase-frequency plots. 


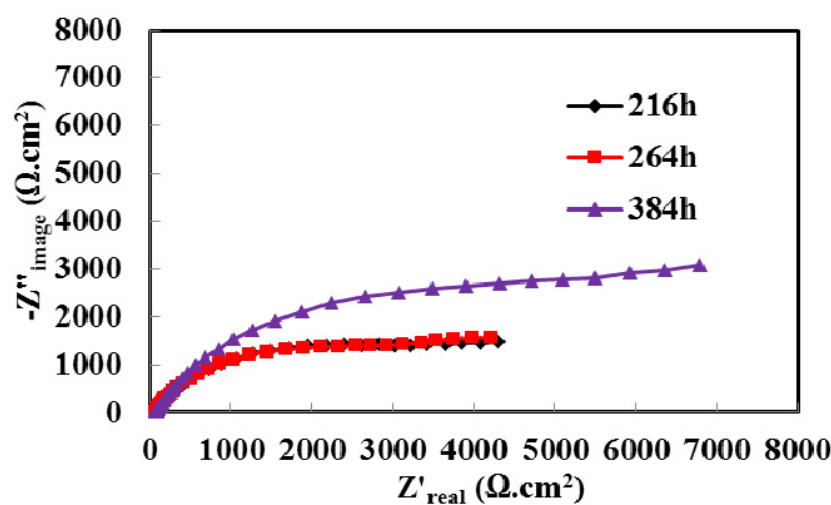

(a)

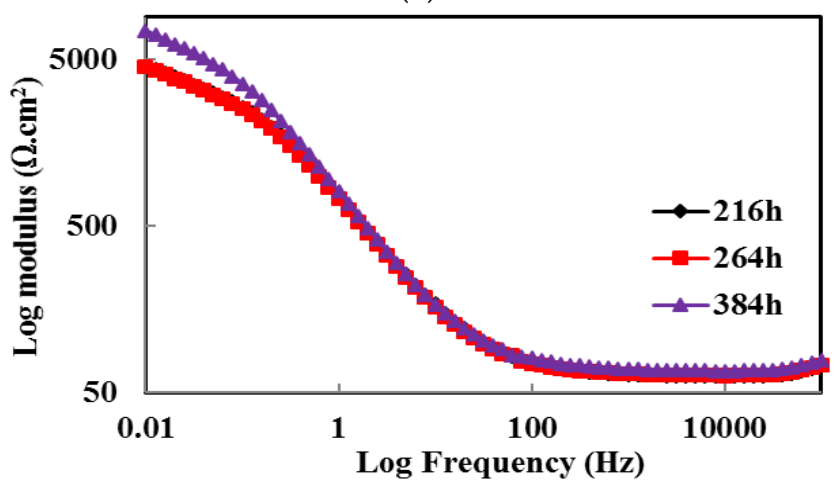

(b)

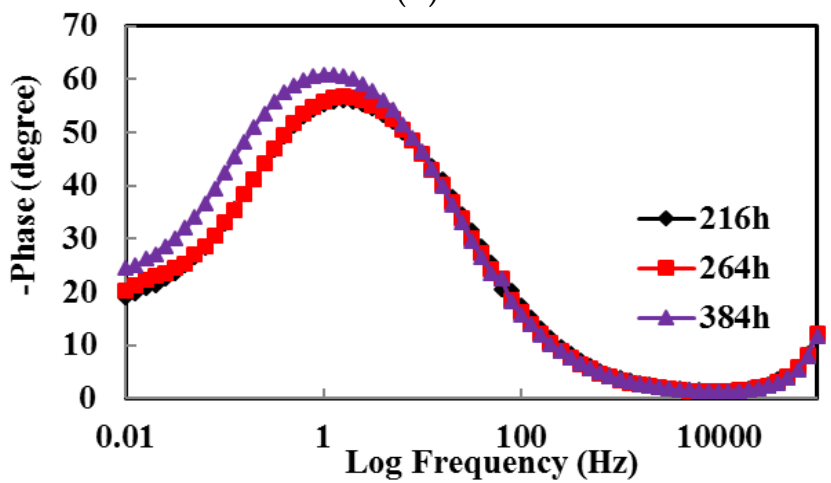

(c)

Figure 8. Electrochemical impedance studies of Al coating in SAE J2334 solution with exposure periods (a) Nyquist, (b) Bode impedance-frequency, (c) Bode phase-frequency plots.

From Figures 7 and 8 it can be observed that the polarization resistance of the coating is continuously increased with exposure periods. From the Nyquist plots (Figures 7a and 8a), the dimension of the semicircle loop has increased considerably with exposure periods, and this is attributed to the formation of a double layer capacitance and a lower corrosion rate $[39,40]$. As the exposure period increases, the passivating behavior of the coating increases, resulting in an increase in polarization resistance. The substantial increase in magnitude of the semi-circle loop results in the decrease of the active surface of the coating and the formation of a protective layer simultaneously. This phenomenon is attributed to the deposition of corrosion products, which block the defects due to a reaction between the coating surface and the ions (chloride and carbonate) available in the solution [41]. After $384 \mathrm{~h}$ (Figure 8a) of exposure, the enlargement of the semi-circle loop is the highest, which means the formation of passive film is uniform, dense and very protective, and that this film exhibited more resistance to electrochemical reaction. 
Figures $7 \mathrm{~b}$ and $8 \mathrm{~b}$ show the typical impedance-frequency Bode plots for coated samples at comparative modes for different exposure periods, and the impedance at the lowest studied frequency $(0.01 \mathrm{~Hz})$ that are increased with the progression of immersion periods of the coating in the solution. The gradual increment of the impedance value with the exposure periods exhibited the formation of a protective passive oxide film on the coating surface. The increment in impedance values are attributed to the growth of passive film thickness and the increase in film resistance itself towards the penetration of aggressive ions through the film [42]. This finding also corroborates the results of the Nyquist plots. The increments of the impedance values are more significant for $384 \mathrm{~h}$ of exposure than for other exposure periods.

Figures $7 \mathrm{c}$ and $8 \mathrm{c}$ of frequency-phase Bode plots show that the maximum phase angle for $1 \mathrm{~h}$ and $384 \mathrm{~h}$ of exposure is $-40^{\circ}$ and $-60^{\circ}$, respectively, and is shifted towards the lower frequency (6 Hz-1 Hz for $1 \mathrm{~h}$ and $4 \mathrm{~Hz}-0.3 \mathrm{~Hz}$ for $384 \mathrm{~h}$ ). The shifting of the phase angle at the lower frequency is attributed to the formation of double layer capacitance and the reduction in the anodic surface area of the coating [43-45]. This phenomenon indicates that the surface was covered with protective and thick passive layers on the coating surface. The corrosion characteristics of the Al coating in the SAE J2334 solution exhibited more passive behavior than in the $3.5 \mathrm{wt}$. \% NaCl solution. This phenomenon is attributed to the presence of bicarbonate and chloride ions in the solution, which is responsible for formation of protective passive film of Al containing carbonate and hydroxides. This mechanism will be described in a subsequent paragraph.

After fitting the impedance data in an appropriate electrical equivalent circuit (Figure 9), this model was also reported by other researchers [46-48]. The impedance data are best fitted in the CPE model because coatings have inhomogeneity, defects and rough surfaces, which allow the solution to penetrate across the coating surface [49-51]. The electrochemical parameters were calculated and the data is presented in Table 5. In Figure 9, $R_{\mathrm{S}}, \mathrm{CPE}_{\mathrm{C}}$ and $R_{\text {pore }}$ are representing solution resistance, coating capacitance and polarization resistance, respectively. From Table 5 it is observed that the $R_{\text {pore }}$ of the Al coating has continuously increased with exposure periods in the SAE J2334 solution and is exhibited due to the formation of more protective passive layers on the coating surface. Since $R_{\text {pore }}$ increases, the $Y_{\mathrm{o}}$ (admittance) should be decreased and it is confirmed by the calculated values of electrical parameters. Initially, the coating surface was rough so that the $Y_{\mathrm{o}}$ was high and indicated higher double layer capacitance [52], but as exposure periods are increased, this value became less. This result indicates that the passive film became non-porous and protective. This observation is exhibited due to the formation of strong passive film on the coating surface. Consequently, the $n$ (dispersion coefficient) for the initial period of exposure is 0.65 , and it indicates inhomogeneity of the coating surface; furthermore, it is increased with exposure periods [53].

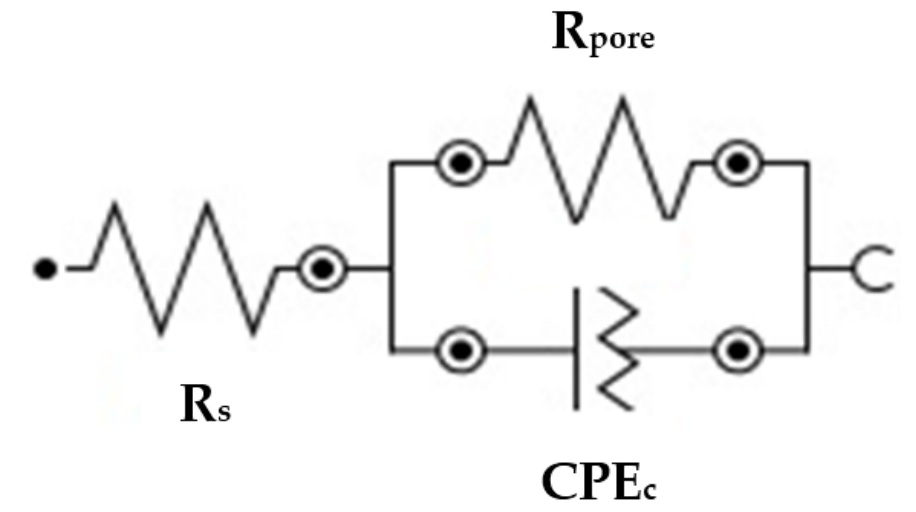

Figure 9. Electrochemical circuit of the corrosion process of Al coating in SAE J2334 solution with exposure periods. 
Table 5. Electrochemical parameters of Al coating extracted after the fitting of EIS data in a constant phase element (CPE) model with exposure periods in SAE J2334 solution.

\begin{tabular}{ccccc}
\hline Exposure Periods $(\mathbf{h})$ & $\boldsymbol{R}_{\mathbf{s}}\left(\boldsymbol{\Omega} \cdot \mathbf{c m}^{\mathbf{2}}\right)$ & $\boldsymbol{R}_{\text {pore }}\left(\boldsymbol{\Omega} \cdot \mathbf{c m}^{\mathbf{2}}\right)$ & $\mathrm{CPE}_{\mathbf{c}} \boldsymbol{Y}_{\mathbf{o}}\left(\boldsymbol{\Omega}^{-1} \cdot \mathbf{c m}^{-2} \cdot \mathbf{s}^{-n}\right)$ & $n$ \\
\hline 1 & 64.15 & 2327.0 & $3.73 \times 10^{-4}$ & 0.65 \\
24 & 62.16 & 2985.1 & $3.70 \times 10^{-4}$ & 0.66 \\
144 & 60.65 & 4005.4 & $3.59 \times 10^{-4}$ & 0.67 \\
216 & 62.44 & 4646.4 & $3.47 \times 10^{-4}$ & 0.73 \\
384 & 69.55 & 7357.9 & $2.85 \times 10^{-4}$ & 0.80 \\
\hline
\end{tabular}

This observation is predicting the surface becoming homogenous with the passage of exposure periods of the coating in the solution. Blucher et al. (2001) and other researchers have observed that for aluminum metal exposed in $\mathrm{NaCl}$ solution polluted by $\mathrm{CO}_{2}$ in the environment, the surface is inhibited by corrosion products due to the cathodic reduction of oxygen and anodic dissolution of metal by high $\mathrm{pH}$ [54-57]. In this study the formation of passive films that stifle the anodic dissolution of coating are as follow:

$$
2 \mathrm{Al}+\mathrm{NaHCO}_{3}+\mathrm{CaCl}_{2}+\mathrm{NaCl}+4 \mathrm{H}_{2} \mathrm{O}+\frac{3}{2} \mathrm{O}_{2} \rightarrow \mathrm{NaAlCO}_{3}(\mathrm{OH})_{2}(\text { Dawsonite })+\mathrm{Al}(\mathrm{OH})_{3}(\text { Bayerite } / \text { Gibbsite })+\mathrm{NaOH}+\mathrm{CaO}+3 \mathrm{HCl}
$$

From the above results it is very important to study the characteristics of passive film, which is being formed on the coating surface during exposure in solution. The morphology of passive film by SEM and nature of this film by XRD and Raman spectroscopy were performed. The XRD was carried out on passive film (plot not shown), which has been formed on the coating surface but was not able to detect the phases present in the passive film. It may be due to the very thin layer of passive film, which may be in nanometers, and using this technique it is not possible to detect the phases available in passive film.

\subsection{Characteristics of Passive Film Formed on the Coating Surface}

\subsubsection{SEM Studies of Passive Film}

The SEM images and EDS spectra of passive film which has been formed on coating surface in the SAE J2334 solution after $384 \mathrm{~h}$ of exposure are shown in Figure 10a,b. From Figure 10a it can be seen that the morphology of passive film is uniform, layered and dense [44]. The growth/orientation of passive film is prohibiting the penetration of other aggressive gases and ions. The presence of $C$, $\mathrm{O}, \mathrm{Na}$ and $\mathrm{Al}$ in EDS spectra (Figure 10b) predicts the phases related to these elements present on passive film. For the evaluation of phases present in passive film, Raman spectra were carried out. For knowing the characteristics of passive film, Raman spectroscopy is a very useful technique and is described in the subsequent paragraph.

\subsubsection{Raman Spectroscopy of Passive Film}

Raman spectroscopy of passive film was carried out after $384 \mathrm{~h}$ of exposure in the SAE J2334 solution and shown in Figure 11. The different phases are observed at different Raman shift, i.e., $570 \mathrm{~cm}^{-1}$ (Gibbsite) [58], $868 \mathrm{~cm}^{-1}$ (Bayerite) [58], $662 \mathrm{~cm}^{-1}, 1405 \mathrm{~cm}^{-1}$ and $1525 \mathrm{~cm}^{-1}$ (Dawsonite) [59]. The intensity of the Raman spectra is weak due to the very low concentrations of phases and film thickness being very low. Therefore, the Raman peaks are not intense. From Raman spectroscopy it is observed that the passive film contains Bayerite $\left(\alpha-\mathrm{Al}(\mathrm{OH})_{3}\right)$, Gibbsite $\left(\gamma-\mathrm{Al}(\mathrm{OH})_{3}\right)$ and Dawsonite $\left(\mathrm{NaAlCO}_{3}(\mathrm{Al})_{2}\right)$. These phases are very protective in nature and once these phases are formed on coating surface they protect the materials from further corrosion. The presence of these phases on the surface of the coating contributed enhanced corrosion resistance properties to the $\mathrm{Al}$ coating exposed in the SAE J2334 solution [60,61]. 

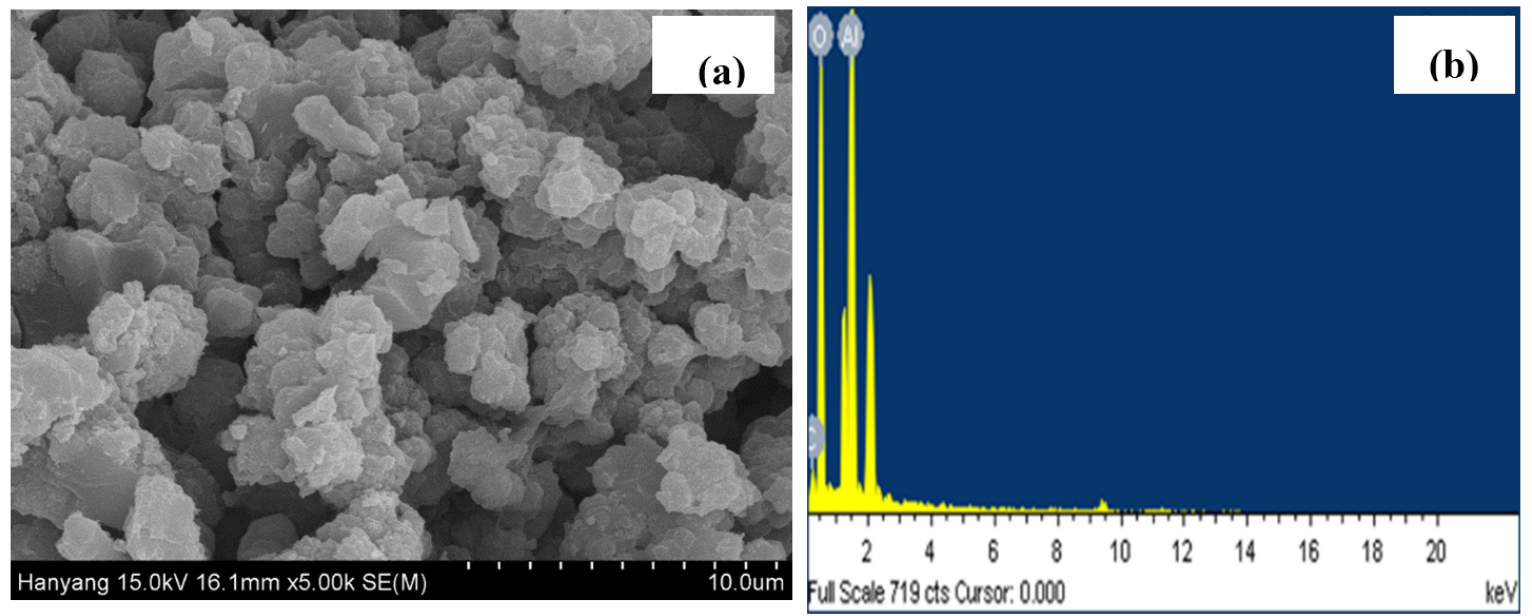

Figure 10. Morphology (a) SEM image and (b) EDS of passive film formed on the Al coating surface after $384 \mathrm{~h}$ of exposure in SAE J2334 solution.

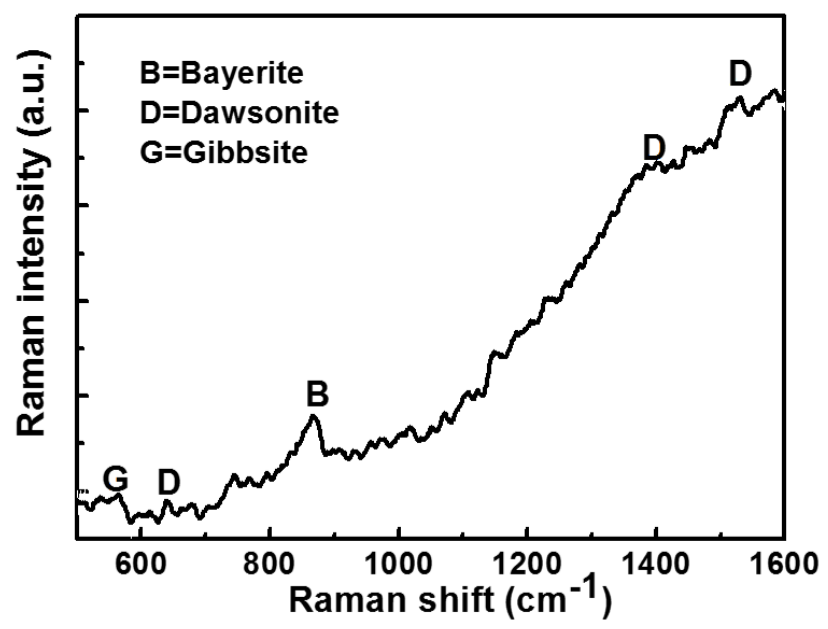

Figure 11. Raman spectroscopy of passive film formed on $\mathrm{Al}$ coating after $384 \mathrm{~h}$ of exposure in SAE J2334 solution.

Dawsonite is thermodynamically very stable and its solubility in any environment is much less [61]. The presence of Dawsonite, Gibbsite and Bayerite on the coating surface after exposure for $384 \mathrm{~h}$ in the SAE J2334 solution justify the findings of the above-mentioned results.

\section{Conclusions}

The following conclusions can be drawn from the above results:

1. The corrosion characteristics of the Al coating applied using the arc thermal metal spray process in the presence of stimulants provide enhanced corrosion resistance properties to the steel substrate with exposure periods in the SAE J2334 solution;

2. The enhanced corrosion resistance properties of the $\mathrm{Al}$ coating is due to presence of $\mathrm{NaCl}, \mathrm{CaCl}_{2}$ and $\mathrm{NaHCO}_{3}$ in the solution, which reduces the anodic surface area of the coating and the cathodic reduction of oxygen by forming a thin layer of protective passive film;

3. Kinetics and the mechanism determined by EIS and potentiodynamic studies suggested the passivating nature of the $\mathrm{Al}$ coating in the presence of carbonate and chloride ions of the SAE J2334 solution with exposure periods; 
4. The morphology of passive films is very dense, layered, thick, compact and adherent to the $\mathrm{Al}$ coating surface;

5. Raman spectroscopy confirmed the formation of Dawsonite, Gibbsite and Bayerite on the Al coating surface. These phases are very protective in nature and sparingly soluble.

Acknowledgments: This research was supported by basic science research program through the National Research Foundation (NRF) of Korea funded by the Ministry of Science, ICT and Future Planning (No. 2015R1A5A1037548).

Author Contributions: J.K.S. conducted the experiments and wrote the initial draft of the manuscript. H.S. Lee designed the experiments. J.K.S. and H.S. Lee analyzed the data and wrote the final manuscript. Mohamed A. Ismail and C. Bhattacharya reviewed and contributed to the final revised manuscript. All authors contributed to the analysis of the data and read the final paper.

Conflicts of Interest: The authors declare no conflict of interest.

\section{References}

1. Jandin, G.; Liao, H.; Feng, Z.Q.; Coddet, C. Correlations between Operating Conditions, Microstructure and Mechanical Properties of Twin Wire Arc Sprayed Steel Coatings. Mater. Sci. Eng. A 2003, 349, 298-305. [CrossRef]

2. Guilemany, J.M.; Miguel, J.M.; Armada, S.; Vizcaino, S.; Climent, F. Use of scanning white light interferometry in the characterization of wear mechanisms in thermal-sprayed coatings. Mater. Charact. 2001, 47, 307-314. [CrossRef]

3. Rhys-Jones, T.N. Thermally sprayed coating systems for surface protection and clearance control applications in aero engines. Surf. Coat. Technol. 1990, 43-44, 402-415. [CrossRef]

4. Pawlowski, L. The Science and Engineering of Thermal Spray Coatings, 2nd ed.; John Wiley \& Sons Ltd.: West Sussex, UK, 2008.

5. Chaliampalias, D.; Vourlias, G.; Pavlidou, E.; Stergioudis, G.; Skolianos, S.; Chrissafis, K. High temperature oxidation and corrosion in marine environments of thermal spray deposited coatings. Appl. Surf. Sci. 2008, 255, 3104-3111. [CrossRef]

6. Choe, H.-B.; Lee, H.-S.; Shin, J.-H. Experimental study on the electrochemical anti corrosion properties of steel structures applying the arc thermal metal spraying method. Materials 2014, 7, 7722-7736. [CrossRef]

7. Krepski, R.P. Thermal Spray: Coating Applications in the Chemical Process Industries; Published for the Materials Technology Institute of the Chemical Process Industries Inc.: St. Louis, MO, USA, 1993; Volume 2, p. 8.

8. Paredes, R.S.C.; Amico, S.C.; d'Oliveira, A.S.C.M. The effect of roughness and pre-heating of the substrate on the morphology of aluminium coatings deposited by thermal spraying. Surf. Coat. Technol. 2006, 200, 3049-3055. [CrossRef]

9. Li, Y.; Liu, J.; Duan, J.; Hou, B. Thermally sprayed aluminium and zinc coatings for tidal zone cathodic protection of offshore platform pile leg. Mater. Perform. 2006, 45, 16-20.

10. Muhamad, H.A.M.; Hayati, S.N.; Kiyai, A.S.; Binti, M.S.N. Thermal arc spray overview. Mater. Sci. Eng. 2013, 46, 1-10. [CrossRef]

11. Jiang, Q.; Miao, Q.; Liang, W.-P.; Ying, F.; Tong, F.; Xu, Y.; Ren, B.-L.; Yao, Z.-J.; Zhang, P.-Z. Corrosion behavior of arc sprayed Al-Zn-Si-RE coatings on mild steel in 3.5 wt. \% NaCl solution. Electrochim. Acta 2014, 115, 644-656. [CrossRef]

12. Valdez, B.; Kiyota, S.; Stoytcheva, M.; Zlatev, R.; Bastidas, J.M. Cerium-based conversion coatings to improve the corrosion resistance of aluminium alloy 6061-T6. Corros. Sci. 2014, 87, 141-149. [CrossRef]

13. Panossian, Z.; Mariaca, L.; Morcillo, M.; Flores, S.; Rocha, J.; Pena, J.J.; Herrera, F.; Corvo, F.; Sanchez, M.; Rincon, O.T.; et al. Steel Cathodic Protection Afforded by Zinc, Aluminium and Zinc/Aluminium Alloy Coatings in the Atmosphere. Surf. Coat. Technol. 2005, 190, 244-248. [CrossRef]

14. Schweitzer, P.A. Atmospheric Corrosion. In Fundamentals of Corrosion Mechanisms, Causes and Preventive Methods; CRC Press, Taylor and Francis Group: Boca Raton, FL, USA, 2009; Chapter 4.

15. Salas, O.; de Troconis, O.; Rojas, D.; Tosaya, A.; Nathalie, R.; Miguel, S. Six-year evaluation of thermal-sprayed coating $\mathrm{Zn} / \mathrm{Al}$ in tropical marine environments. Int. J. Corros. 2012. [CrossRef]

16. Steffens, H.D.; Babiak, Z.; Wewel, M. Recent developments in arc spraying. IEEE Trans. Plasma Sci. 1990, 18, 974-975. [CrossRef] 
17. Davis, J.R. Surface Engineering for Corrosion and Wear Resistance; ASM International: Materials Park, $\mathrm{OH}$, USA, 2001.

18. Muhamad, H.A.M.; Hayati, S.N.; Kiyai, A.S.; Binti, M.S.N. Critical process and performance parameters of thermal arc spray coating. Int. J. Mater. Eng. Innov. 2014, 5, 12-27.

19. ASTM D4541-09e1, Standard Test Method for Pull-Off Strength of Coatings Using Portable Adhesion Testers; ASTM International: West Conshohocken, PA, USA, 2009. [CrossRef]

20. Standard SAE J2334; Society of Automotive Engineers (SAE): Warrendale, PA, USA, 2003.

21. Saha, J.K.; Mitra, P.K.; Paul, S.; Singh, D.D.N. Performance of different organic coatings on steel substrate by accelerated and in atmospheric exposure tests. Indian J. Chem. Technol. 2010, 17, 102-110.

22. Singh, D.D.N.; Dey, M.; Singh, V. Role of Buffering and Complexing Agents in Zinc Plating Chloride Baths on Corrosion-Resistance of Produced Coatings. Corrosion 2002, 58, 971-980. [CrossRef]

23. Singh, D.D.N.; Yadav, S.; Saha, J.K. Role of climatic conditions on corrosion characteristics of structural steels. Corros. Sci. 2008, 50, 93-110. [CrossRef]

24. Townsend, H.E.; Simpson, M.W.; van der Linde, W.B.; McCune, D.C. License Plate Cosmetic Corrosion Test of Automotive Coated Steel Sheet. Corrosion 1999, 55, 406-411. [CrossRef]

25. Abedi, E.E.; Hamidreza, S.; Mohamad, A.G.; Javad, M.; Larry, P. Study of Corrosion Behavior of Arc Sprayed Aluminum Coating on Mild Steel. J. Therm. Spray Technol. 2012, 21, 1195-1202. [CrossRef]

26. Han, M.-S.; Woo, Y.-B.; Ko, S.-C.; Jeong, Y.-J.; Jang, S.-K.; Kim, S.-J. Effects of thickness of Al thermal spray coating for STS 304. Trans. Nonferr. Met. Soc. China 2009, 19, 925-929. [CrossRef]

27. Torres, B.; Campo, M.; Urena, A.; Rams, J. Thermal spray coatings of highly reinforced aluminium matrix composites with sol-gel silica coated SiC particles. Surf. Coat. Technol. 2007, 201, 7552-7559. [CrossRef]

28. Deshpande, S.; Kulkami, A.; Sampath, S.; Herman, H. Application of image analysis for characterization of porosity in thermal spray coatings and correlation with small angle neutron scattering. Surf. Coat. Technol. 2004, 187, 6-16. [CrossRef]

29. Celik, E.; Ozdemir, I.; Avcic, E.; Tsunekawa, Y. Corrosion behaviour of plasma sprayed coatings. Surf. Coat. Technol. 2005, 193, 297-302. [CrossRef]

30. Kawakita, J.; Kuroda, S.; Fukushima, T.; Kodama, T. Corrosion resistance of HVOF sprayed HastelloyC nickel base alloy in seawater. Corros. Sci. 2003, 45, 2819-2835. [CrossRef]

31. Baxter, C.S. Thermal spray inspection method and training requirement. Mater. Perform. 1997, 36, 31-32.

32. Wixson, D. Thermal spray deposits shield structure from corrosion. Weld. J. 2009, 88, 46-48.

33. Salman, S.A.; Ichino, R.; Okido, M.A. Comparative electrochemical study of AZ31 and AZ91 magnesium alloy. Int. J. Corros. 2010, 2010, 412129. [CrossRef]

34. Dean, S.W. Electrochemical methods of corrosion testing. In Electrochemical Techniques for Corrosion; Baboian, R., Ed.; NACE: Houston, TX, USA, 1977; pp. 52-60.

35. Dzhurinskiy, D.; Maeva, E.; Leshchinsky, E.; Maev, R.G. Corrosion protection of light alloys using low pressure cold spray. J. Therm. Spray Technol. 2012, 21, 304-313. [CrossRef]

36. Moran, A.L.; Shaw, B.A. In Situ Evaluation of Oxide Formation in Aluminum Thermal Spray Coatings. J. Electrochem. Soc. 1988, 135, 2773-2774. [CrossRef]

37. Hurlen, T.; Haijg, A.T. Corrosion and passive behavior of Aluminum in weakly alkaline solution. Electrochem. Acta 1984, 29, 1833-1838.

38. Liu, Y.; Visser, P.; Zhou, X.; Lyon, S.B.; Hashimoto, T.; Curioni, M.; Gholinia, A.; Thompson, G.E.; Smyth, G.; Gibbon, S.R.; et al. Protective Film Formation on AA2024-T3 Aluminum Alloy by Leaching of Lithium Carbonate from an Organic Coating. J. Electrochem. Soc. 2016, 163, C45-C53. [CrossRef]

39. Ishizaki, T.; Masuda, Y.; Teshima, K. Composite film formed on magnesium alloy AZ31 by chemical conversion from molybdate/phosphate/fluorinate aqueous solution toward corrosion protection. Surf. Coat. Technol. 2013, 217, 76-83. [CrossRef]

40. Wen, J.B.; Ma, J.J.; He, J.G. Al-Base Sacrificial Anode Material for Corrosion Protection; Chemical Industry Press: Beijing, China, 2012; pp. 67-79.

41. Ryl, J.; Wysocka, J.; Jarzynka, M.; Zielinski, A.; Orlikowski, J.; Darowicki, K. Effect of native air-formed oxidation on the corrosion behaviour of AA 7075 aluminium alloys. Corros. Sci. 2014, 87, 150-155. [CrossRef] 
42. Onofre-Bustamante, E.; Dominguez-Crespo, M.A.; Torres-Huerta, A.M.; Olvera-Martinez, A.; Genesca-Llongueras, J.; Rodriguez-Gomez, F.J. Characterization of cerium-based conversion coatings for corrosion protection of AISI-1010 commercial carbon steel. J. Solid State Electrochem. 2009, 13, 1785-1799. [CrossRef]

43. Stefanov, P.; Atanasova, G.; Stoychev, D.; Marinova, T.S. Electrochemical deposition of $\mathrm{CeO}_{2}$ on $\mathrm{ZrO}_{2}$ and $\mathrm{Al}_{2} \mathrm{O}_{3}$ thin films formed on stainless steel. Surf. Coat. Technol. 2004, 180-181, 446-449. [CrossRef]

44. Dongrui, Y.; Omar, R.; Homero, $\mathrm{C}$. $\mathrm{FeCO}_{3}$ layer evolution for API 5L X52 steel in carbon dioxide-saturated $\mathrm{NaCl}$ brine in the presence of 1-decyl-3-methylimidazolium chloride. Corros. Sci. 2014, 87, 40-50.

45. Verdian, M.M.; Raeissi, K.; Salehi, M. Electrochemical Impedance Spectroscopy of HVOF-Sprayed NiTi Intermetallic Coatings Deposited on AISI 1045 Steel. J. Alloy. Compd. 2010, 507, 42-46. [CrossRef]

46. Gudic, S.; Radosevic, J.; Kliskic, M. Study of passivation of Al and Al-Sn alloys in borate buffer solutions using electrochemical impedance spectroscopy. Electrochim. Acta 2002, 47, 3009-3016. [CrossRef]

47. Martin, F.J.; Cheek, G.T.; O'Grady, W.E.; Natishan, P.M. Impedance studies of the passive film on aluminium. Corros. Sci. 2005, 47, 3187-3201. [CrossRef]

48. Liu, Y.J.; Wang, Z.Y.; Ke, W. Study on influence of native oxide and corrosion products on atmospheric corrosion of pure Al. Corros. Sci. 2014, 80, 169-176. [CrossRef]

49. Maddela, S.; O’Keefe, M.J.; Wang, Y.M.; Kuo, H.H. Influence of surface pretreatment on coating morphology and corrosion performance of cerium-based conversion coatings on AZ91D alloy. Corrosion 2010, 66, 1-8. [CrossRef]

50. Bastidas, J.M.; Polo, J.L.; Torres, C.L.; Cano, E. A study on the stability of AISI 316L stainless steel pitting corrosion through its transfer functions. Corros. Sci. 2001, 43, 269-281. [CrossRef]

51. Flores, J.F.; Olaya, J.J.; Colas, R.; Rodil, S.E.; Valdez, B.S.; Fuente, I.G. Corrosion behaviour of TaN thin PVD films on steels. Corros. Eng. Sci. Technol. 2006, 41, 168-176. [CrossRef]

52. Cox, B.; Wong, Y.M. Simulation porous oxide films on Zirconium alloys. J. Nucl. Mater. 1995, 218, 324-334. [CrossRef]

53. Singh, J.K.; Singh, D.D.N. The nature of rusts and corrosion characteristics of low alloy and plain carbon steels in three kinds of concrete pore solution with salinity and different pH. Corros. Sci. 2012, 56, 129-142. [CrossRef]

54. Blucher, D.B.; Lindstrom, R.; Svensson, J.E.; Johansson, L.G. The Effect of $\mathrm{CO}_{2}$ on the NaCl-Induced Atmospheric Corrosion of Aluminum. J. Electrochem. Soc. 2001, 148, B127-B131. [CrossRef]

55. Lin, $\mathrm{C}$; $\mathrm{Li}, \mathrm{X}$. Role of $\mathrm{CO}_{2}$ in the initial stage of atmospheric corrosion of AZ91 magnesium alloy in the presence of NaCl. Rare Met. 2006, 25, 190-196. [CrossRef]

56. Maier, B.; Frankel, G.S. Behavior of Magnesium-Rich Primers on AA2024-T3. Corrosion 2011, 67, 1-15. [CrossRef]

57. Pathak, S.S.; Blanton, M.D.; Mendon, S.K.; Rawlins, J.W. Mineralogical Transformation and Electrochemical Nature of Magnesium-Rich Primers during Natural Weathering. Metals 2014, 4, 322-334. [CrossRef]

58. Ruan, H.D.; Frost, R.L.; Kloprogg, J.T. Comparison of the Raman spectra of Bayerite, Boehmite, Diaspore and Gibbsite. J. Raman Spectrosc. 2001, 32, 745-750. [CrossRef]

59. Frost, R.L.; Bouzaid, J.M. Raman spectroscopy of Dawsonite $\mathrm{NaAl}\left(\mathrm{CO}_{3}\right)(\mathrm{OH})_{2}$. J. Raman Spectrosc. 2007, 38, 873-879. [CrossRef]

60. Pascale, B.; Palmer, D.A.; Anovitz, L.M.; Juske, H. Dawsonite synthesis and re-evaluation of its thermodynamic properties from solubility measurements: Implications for mineral trapping of $\mathrm{CO}_{2}$. Geochim. Cosmochim. Acta 2007, 71, 4438-4455.

61. Ferrante, M.J.; Stuve, J.M.; Richardson, D.W. Thermodynamic Data for Synthetic Dawsonite; Bureau of Mines: Washington, DC, USA, 1976; p. 13.

(C) 2016 by the authors; licensee MDPI, Basel, Switzerland. This article is an open access article distributed under the terms and conditions of the Creative Commons by Attribution (CC-BY) license (http://creativecommons.org/licenses/by/4.0/). 